\title{
Development of the circumpolar territories of the Russian Federation
}

\author{
Tatiana Kulagina, Vladimir Kulagin*, and Valerii Tereshkov \\ Siberian Federal University, 660041 Krasnoyarsk, Russia
}

\begin{abstract}
This article considers the possibility of sustainable development of the eastern territories of Russia from the Ural to the Pacific Ocean, which concentrate the overwhelming part of the country's natural resources. An approach for the development of economic policy, making optimal economic decisions in the field of assessing the prevented damage is presented. It is noted that the underestimation of environmental parameters leads to a distortion of the analysis of economic development through traditional indicators of the gross national product, etc., the growth of which may cover the environmental degradation. A new method for assessing the prevented economic damage during environmental protection measures was proposed, which takes into account various technical and design features of dust cleaning systems. By using the proposed methodology it seems possible to assess the expected damage to the environment, the economic efficiency of the project being developed, and select the most profitable area for the location of dust-cleaning equipment at the design stage. A criterion for evaluating the effectiveness when comparing installations of various designs were proposed.
\end{abstract}

\section{Introduction}

At this stage of the social and economic development of the Russian Federation, the agenda includes a national comprehensive project for the modernization and development of the eastern territories of Russia from the Ural to the Pacific Ocean, which concentrate the overwhelming majority of the country's natural resources. The possibility of sustainable development of these territories and Russia as a whole in the 21 st century is determined by a set of existing factors: resource self-sufficiency; military potential to protect national interests and resources; high educational level of the population; scientific researches across-theboard; the presence of territories of prospective development. These factors form the necessary conditions for successful development but must be supplemented by a system of organizational, programmatic, scientific, and technical measures that take into account the peculiarities of the eastern regions of Russia (geographic, climatic, transport, energy, etc.). In order to effectively implement the planned investment projects, special attention should also be paid to scientific and educational aspects and factors that ensure the accelerated development of territorial and industrial complexes (clusters, territories of priority development). This implies the need to develop and implement a new state scientific and

\footnotetext{
* Corresponding author: $\underline{\text { v.a.kulagin@mail.ru }}$
} 
technical policy for the further development of the northern and eastern regions of Russia, which should be based on the following provisions:

- the technical level of the existing systems of energy, heat and water supply, wastewater treatment technologies, and waste disposal (domestic, industrial) used in the North is extremely low and requires a radical change;

- the tasks of ensuring man-made, environmental, and energy safety of complex technical objects and territories of cold climate regions come to the fore;

- resolving the dilemma of contradictions - the requirements for the need for industrial development and the assimilation of new territories and the requirements for ensuring natural, man-made, and environmental safety is only possible with an integrated approach for planning and managing development risks based on interdisciplinary research that can ensure the successful promotion of modern objects of the technosphere in the northern and arctic regions;

- massive use of machines, structures, and equipment, the construction of unique engineering structures, crucial and hazardous industrial facilities is possible only with the widespread use of innovative equipment and technologies, which requires appropriate scientific, educational, and technological support at the stages of their creation, production and operation.

The development of the technogenic sphere in the northern regions leads to diametrically opposite consequences: on the one hand, the infrastructure develops, new minerals and human resources are involved in the production process, employment of the population and the growth of the regional economy is ensured, the living standard of the population rises; on the other hand, industrial objects created by humans, the operation of which is associated with an increased risk of man-made accidents and disasters, began to pose a real danger to the fragile northern nature and humans themselves.

In this regard, the task of ensuring technogenic, environmental and energy security of complex technical objects and circumpolar regions as a whole comes to the fore. The problem of the development of traditional and new scientific directions in the interests of the northern territories of Russia becomes more relevant, which is due to the presence in the region of a large number of objects in the permafrost zone, accumulated environmental damage, increased man-made danger and risks of emergencies. The need to develop the northern and arctic territories on the basis of high technologies in the field of technosphere security is of strategic importance for the stable and long-term growth of the Russian economy, ensuring national security and maintaining the political authority of Russia in the international arena.

The purpose of this work is to create and disseminate new knowledge and technologies that contribute to sustainable development in accordance with the national security strategy of Russia on the fundamental functions of the state: improving the living standards of the population and ensuring national security, taking into account systemic strategic risks in forecasting and planning the development of Russia.

The problem of intensive development of the resources of Siberia and the North has become fundamentally urgent for Russia in connection with the depletion of the main explored reserves of natural resources in its European part. Accelerated development of the North and the Arctic, including the coast and shelf of the Arctic seas, aimed at strengthening the economic potential of Russia, means the development of basic industries (mining, oil, and gas) with the creation of appropriate infrastructure, transport, communications. At the same time, it is necessary to take into account the extreme climatic, complex mining and geological, and extremely unfavorable social and economic conditions for conducting industrial work. The problem is aggravated by the exhaustion of the calculated resource of a large part of the existing technical objects, including pipeline systems, industrial equipment, and machinery. 
With that in mind, it is possible to formulate scientific directions, within the framework of the list of critical technologies, which should be focused on in the first place and in which certain experience has been accumulated - these are:

- Research of reducing the radiation hazard when handling radioactive and highly hazardous toxic waste [1-8];

- Technologies for conditioning and disinfection of process and wastewater in the energy sector, water supply, and sewerage [9-14];

- Theoretical and experimental studies of multiphase supercavitation flows [15-21];

- Development of applications of cavitation technology in various industries [22, 23];

- Analysis of the efficiency of using all types of energy resources at the stages of receipt, transportation, storage, consumption of heat and electric energy and utilization in order to develop new energy-saving technologies in energy and heat technology; research in the field of creating new types of emulsified (suspension) fuel mixtures [24-32].

One of the most important tasks from this list is the reduction of harmful emissions into the atmosphere, the assessment of the prevented damage to the environment, and, as a consequence, the assessment of the effectiveness of environmental protection measures based on the performance indicators of gas cleaning facilities.

\section{Research methodology}

Let's consider methods for evaluating the effectiveness of systems for cleaning atmospheric emissions. The complex of environmental measures should ensure compliance with regulatory requirements for the quality of the environment that meet the interests of protecting the human health and the environment, taking into account the future changes due to the development of production, as well as obtaining the maximum national economic effect from improving the state of the environment, saving and optimal use of natural resources. Achievement of these goals is assessed using indicators of social and economic results of environmental protection measures at the ecological, social, medical, and economic levels [33]. The effectiveness of environmental protection measures at the economic level lies in saving or preventing the loss of natural resources, social labor in the production and nonproduction spheres of the national economy, as well as in the sphere of personal consumption, achieved through the implementation of environmental protection measures.

An amount that determines the damage to the noobiogeocenosis from disturbances and pollution is proposed as an integral assessment of the consequences of each type of production impact on nature and the human environment.

$$
\mathrm{y}_{\Sigma}=\sum_{i=1}^{n} \mathrm{y}_{\text {экон }}+\sum_{j=1}^{m} \mathrm{y}_{\text {сон }}+\sum_{k=1}^{I} \mathrm{y}_{\text {нек }}
$$

where $n, m, I$ - the number of consequences of changes in components in the noobiogeocenosis of one species. The cost expression of damage in the form of additional costs in the national economy as a whole or at an individual enterprise is feasible only if it is possible to quantify the consequences of the harmful effects of human economic activity and express them through the cost of work to prevent or eliminate them.

Based on the general approach to the assessment of natural benefits and the economics of environmental management [33], an expression was found to determine the damage caused as a result of harmful emissions into the atmosphere:

$$
\mathrm{y}_{m}=\frac{c \sum_{i=1}^{N} A_{i}\left(1-\eta_{i}\right) m_{0 i}}{\sum_{i=1}^{N} m_{0 i}-\sum_{i=1}^{N}\left(1-\eta_{i}\right) m_{0 i}},
$$


where $N$ - the total number of pollutants; $A_{i}$ is the indicator of the relative activity of the $i$-type contaminant, t/year; $m_{i}$ - the mass of the gas release of the $I$-type contaminant into the atmosphere, $\mathrm{t} /$ year; $m_{0 i}$ - initial dust content of the $i$-th component; $\eta_{i_{-}}$- the degree of separation of the $i$-th component in the dust collection system; $c--$ emission weight component. In industrial practice, one should strive to minimize damage from air pollution: $\mathrm{y}_{m} \rightarrow \min$.

Usually, the weight fraction of the $c_{i} i$-th component in the initial gas stream is known. It's obvious that $\sum_{i=1}^{N} c_{i}=1$. If the total initial dustiness of the gas flow is estimated by the $K_{0}$ value, then $m_{0 i}=K_{0} c_{i}$ and function (2) can be expressed through the initial parameters of the stream to be cleaned

$$
\mathrm{y}_{m}=\frac{c \sum_{i=1}^{N} A_{i}\left(1-\eta_{i}\right) c_{i}}{\sum_{i=1}^{N} c_{i}-\sum_{i=1}^{N}\left(1-\eta_{i}\right) c_{i}} .
$$

Let's introduce the concept of the average reduced indicator of the aggressiveness of a contaminant in the form of a ratio

$$
A_{\mathrm{cp}}=\frac{1}{N} \sum_{i=1}^{N} A_{i} c_{i} .
$$

Assuming that all components of the gas flow are captured to the same extent $\left(\eta_{i}=\eta_{\mathrm{cp}}\right)$, we get

$$
\mathrm{y}_{m}=\frac{c\left(1-\eta_{\mathrm{cp}}\right) A_{\phi}}{\eta_{\mathrm{cp}}}
$$

As follows from the obtained formula (5), the damage from atmospheric emissions in the adopted formulation is mainly determined by the slip and the indicator of the contaminant aggressiveness. Note that the damage caused decreases in proportion to the increase in the value

$$
E_{\ni}=\frac{\eta_{\mathrm{cp}}}{\left(1-\eta_{\mathrm{cp}}\right) A_{\mathrm{cp}} c},
$$

which is considered a criterion for the environmental efficiency of the gas cleaning system [33]. The criteria for the relative ecological efficiency of the gas cleaning system are written in the form of the ratio of functions (6) formed for competing options, one of which is taken as the basic $E_{\mathrm{e} 0}$ :

$$
\theta_{э}=\frac{E_{э 1}}{E_{э 0}} .
$$

When comparing dust collection systems intended for placement at the same enterprise, the initial parameters are the same, which makes it possible to present the criterion of the relative environmental efficiency of the gas cleaning system in a simplified form:

$$
\theta_{\ni}=\frac{\eta_{\mathrm{cp} 1}}{\eta_{\mathrm{cp} 0}} \cdot \frac{1-\eta_{\mathrm{cp} 0}}{1-\eta_{\mathrm{cp} 1}} .
$$


This approach allows reducing correlation (7) to the technological criterion (8), which is the ratio of the separating capabilities of the compared variants of dust collection systems and solid-phase slip.

\section{Study results}

Let's assess the effectiveness of environmental protection measures based on the performance indicators of the gas treatment facility. According to the standard methodology and industryspecific methods developed on its basis or similar in quality of the results obtained, the economic feasibility of environmental protection measures in relation to dust treatment plants is determined by the annual economic effect $\mathrm{E}$, calculated with the formula in which costs $\mathrm{C}$ are represented as the sum of operating costs $\mathrm{O}$ and capital investments I for environmental protection measures:

$$
\mathrm{C}=\mathrm{O}+\mathrm{D}+E_{\mathrm{n}} \cdot \mathrm{I},
$$

where $\mathrm{C}$ - the unit cost of production excluding damage; D - damage due to pollution of the atmosphere, water, and soil; $E_{\mathrm{n}}$ - standard efficiency ratio; $E_{\mathrm{n}}=0.15$; I - specific capital investments. To assess air pollution, the method of aggregated calculation of specific damage $D_{\text {atm }}$ (rubles/year), caused by the release of any source is used according to the formula:

$$
\mathrm{D}_{\mathrm{atm}}=\gamma \sigma f M \text {. }
$$

Here $\gamma$ is a constant numerically equal to 2.4 rubles/tonne conv. t. after 1985 (its value changes depending on the rise in prices; its value was calculated on the assumption that all types of atmospheric emissions in one way or another come to the water, and the cost of pure water is fixed); $\sigma$ - an indicator of the territory (or coefficient of relative hazard), on which the source of pollution is located, distinguishing between recreation areas, large cities or garden plots;

$$
\sigma=\frac{1}{S_{3 \mathrm{~A} 3}} \sum_{j=1}^{k} S_{j} \sigma_{j}
$$

where $S_{\text {acz }}$ - the area of the active contamination zone (ACZ) of the $i$ type, determined by a special method; $k$ - the total number of types of territories included in the ACZ; $S_{j}$ - the area of the $j$-th part of the ACZ; $\sigma_{j}$ - value $\sigma$ for the $j$-th type of territory; $f$-a coefficient that takes into account the nature of dispersion of contaminants in the atmosphere (associated with the physical properties of the emission, for example, with the dispersion of dust, the height of the chimney, etc.); $M$ - the reduced mass of the annual emission of pollution from the source into the atmosphere, $\mathrm{t}$ conv. tons/year;

$$
M=\sum_{i=1}^{N} A_{i} m_{i} .
$$

The goal function of at least reduced costs was formulated in the development of a technical and economic assessment of heat and mass transfer equipment [33]. In this case, the prevented damage $\mathrm{D}_{\mathrm{pr}}$ is calculated on the assumption that all components in the process emissions are captured to the same extent. This allows the task to be reduced to process criteria while reducing the scope of the results for dry dust collection systems. Nevertheless, the developed approaches allow, based on correlation (9) and (10), to propose criteria for the technical and economic assessment of environmental protection measures.

Before proceeding with the development of criteria for the technical and economic efficiency of gas treatment facilities, we note that the values in expression (9) are presented in absolute form, which makes them contradictory in some cases. Indeed, the annual 
economic effect $\mathrm{E}$ depends on the production volume. Therefore, the damage to the environment from high-tech large-tonnage production may turn out to be greater in absolute numbers than from a small enterprise. This contradiction is removed by switching to relative values, for example, calculated per unit mass of the captured product.

Let's assume the individual components in expression (9) through the design and operating parameters of the gas cleaning system. Then, according to the enlarged methodology for assessing the reduced damage to air pollution, we calculate

$$
\mathrm{y}_{m}=\frac{\gamma \sigma f \sum_{i=1}^{N} A_{i} m_{i}}{\sum_{i=1}^{N}\left(m_{0 i}-m_{i}\right)},
$$

where $\gamma, \sigma, f$ - coefficients calculated according to certain rules [33]; $A_{i}$ - an indicator of aggressiveness. Let's express the initial mass of the $i$ th product as

$$
m_{0 i}=C_{0 i} Q \tau
$$

Here, $C_{0 i}$ - the initial concentration of the $i$ th component in fractions of a unit; $Q$ - the mass gas productivity of the facility, $\mathrm{t} / \mathrm{h} ; \tau$ - operating time of the catching system, $\mathrm{h} /$ year.

The annual emission mass of the $i$-th component is determined by the slip through the collecting system. Let the degree of catching the $i$-th component $\eta$, then

$$
m_{i}=m_{0 i}\left(1-\eta_{i}\right)
$$

therefore, the difference in the formula

$$
m_{0 i}-m_{i}=m_{0 i} \eta_{i}
$$

is the amount of the product caught, $t$ /year. Therefore, taking into account (14) - (16)

$$
\mathrm{y}_{m}=\frac{\gamma \sigma f \sum_{i=1}^{N} A_{i} C_{0 i} Q \tau\left(1-\eta_{i}\right)}{\sum_{i=1}^{N} C_{0 i} Q \tau \eta_{i}} .
$$

After taking the constants outside the summation signs, we get

$$
\mathrm{y}_{m}=\frac{\gamma \sigma f \sum_{i=1}^{N} A_{i} C_{0 i}\left(1-\eta_{i}\right) .}{\sum_{i=1}^{N} C_{0 i} \eta_{i}}
$$

Thus, the reduced damage from atmospheric pollution turns out to be proportional to the slip, the indicator of the relative aggressiveness $A_{i}$ and is inversely proportional to the degree of capture.

Let's calculate the costs of carrying out environmental protection measures according to dependence (9) and refer them to the unit mass of the captured products. Operating costs $\mathrm{O}$ will be defined as the sum of energy costs (EL), depreciation deductions (DD), and cost of losses (CL). The latter values are proportional to capital investments and can be found together with them by introducing a correction factor. Taking into account that $\mathrm{DD}=\mathrm{I} \cdot \mathrm{NA}$,

$$
\mathrm{C}=\mathrm{EL}+\mathrm{I} \cdot \mathrm{NA}+\mathrm{CL}+E_{\mathrm{n}} \mathrm{I}
$$

where DR is the depreciation rate $(10 \%)$, or

$$
\mathrm{C}=\mathrm{EL}+\mathrm{CL}+E \mathrm{I} \text {, }
$$

where $E=E_{\mathrm{n}}+\mathrm{NA}$. 
Since we consider the equipment that does not produce the final product, CLs can be excluded from the analysis. For operating industries, the CL indicator, in this case, should be replaced by the unit cost of fines.

$$
\mathrm{EL}=\mathrm{P}_{\mathrm{e}} \cdot \Delta N \cdot 10^{3},
$$

where $\Delta N$ - the specific energy consumption per unit mass of gas, $\mathrm{J} / \mathrm{kg} ; \mathrm{P}_{\mathrm{e}}$ - the price of electricity, rubles/J; $10^{3}$ - conversion factor, RUB/t.

Let's calculate the specific energy consumption $\Delta H$ from the Bernoulli equation written for the inlet and outlet sections of the gas duct, the diameters of which are assumed to be the same. Neglecting the difference in the cross-sectional levels due to the low gas density, we get

$$
\Delta N=\Delta p / \rho_{\mathrm{g}},
$$

where $\Delta p$ - the hydraulic resistance of the gas treatment facility; $\rho_{\mathrm{g}}$ - gas flow density, $\mathrm{kg} / \mathrm{m}^{3}$. The annual mass gas productivity of the facility is found as

$$
G_{\Gamma}=\rho_{\mathrm{r}} Q \tau 10^{3},
$$

then the annual energy consumption will be

$$
\mathrm{EL}=\mathrm{P}_{\mathrm{e}} \Delta p Q \tau \cdot 10^{3} .
$$

Taking into account the electricity cost per unit mass of the captured material $\mathrm{S}_{\mathrm{en}}$ when using correlation (14), (16), (24) are

$$
Ц_{э н}=Ц_{\ni} \frac{\Delta p 10^{3}}{\sum_{i=1}^{N} C_{0 i} \eta_{i}} .
$$

After substituting (25) into (9), taking into account (20), we get

$$
3=Ц_{\ni} \frac{\Delta p 10^{3}}{\sum_{i=1}^{N} C_{0 i} \eta_{i}}+E K^{\prime}
$$

Capital investments are calculated by calculating the cost of building gas treatment facilities as

$$
\mathrm{K}=\frac{\bigsqcup_{\text {уст }}}{\sum_{i=1}^{N} C_{0 i} Q \tau \eta_{i}}=\frac{Ц_{\text {уст }}}{G_{\text {тв }}}
$$
get

where $\mathrm{P}_{\mathrm{fc}}$ is the price of the catching facility, rubles. After substituting (27) into (26), we

$$
3=Ц_{3} \frac{\Delta p}{\sum_{i=1}^{N} C_{0 i} \eta_{i}}+\frac{E Ц_{\text {уст }}}{\sum_{i=1}^{N} C_{0 i} Q \tau \eta_{i}}
$$

or

Then

$$
3=\frac{1}{\sum_{i=1}^{N} C_{0 i} \eta_{i}}\left(Ц_{3} \Delta p+\frac{E Ц_{\mathrm{ycr}}}{Q \tau}\right) \cdot
$$

$$
Э=\mathrm{y}_{m}-3=\frac{1}{\sum_{i=1}^{N} C_{0 i} \eta_{i}}\left(\gamma \sigma f \sum_{i=1}^{N} A_{i} C_{0 i}\left(1-\eta_{i}\right)-Ц_{9} \Delta p-\frac{E Ц_{\mathrm{ycr}}}{Q \tau}\right) .
$$




\section{Result discussion}

The same phenomenon (process, technology) can be judged based on the assessment of various parameters (design dimensions, operating characteristics, etc.). The most obvious is the criterion assessment of the object under consideration [33]. Here, we are based on the assumption that each alternative can be evaluated with a specific number (criterion value), and the comparison of alternatives is reduced to a comparison of the corresponding numbers. By the criterion, we mean the value of the number required to compare two or more different options for technical solutions. The prevented damage is the difference between the damage of the base case (index 0) and the new one (index 1). Thus, the target function can be represented as the prevented damage per unit mass of the captured product from correlation (17) as

$$
\mathrm{y}_{\text {пр }}=\gamma \sigma f\left[\frac{\sum_{i=1}^{N} A_{i} C_{0 i}\left(1-\eta_{i 0}\right)}{\sum_{i=1}^{N} C_{0 i} \eta_{i 0}}-\frac{\sum_{i=1}^{N} A_{i} C_{0 i}\left(1-\eta_{i 1}\right)}{\sum_{i=1}^{N} C_{0 i} \eta_{i 1}}\right] .
$$

In industrial practice, one should strive to increase the value of Control $\left(\mathrm{D}_{\mathrm{pr}}\right.$ $\left(\mathrm{D}_{\mathrm{pr}} \rightarrow\right.$ max). With the introduction of the average indices $A_{\mathrm{m}}$ and $\eta_{\mathrm{m}}$, expression (17) is transformed into the one obtained earlier for dust collectors. Assessment of the economic efficiency of environmental protection measures based on the above-mentioned dependencies does not cause any difficulties in assessing the existing gas cleaning systems. When it comes to modernizing facilities in the same area, the task is simplified: many coefficients are reduced. If the comparison is made for devices in different regions, there is a difference in the coefficients $\sigma$ and $f$. The avoided damage is calculated by subtracting the damage (smaller) after the improvement from the previous one, and the costs are determined by the cost of the modernization. The situation becomes more complicated when comparing different gas cleaning systems.

The concept of prevented damage $\mathrm{D}_{\mathrm{pr}}$ has already incorporated the indicators of facilities, in particular the degree of separation of containment. In such a setting, it becomes not entirely clear what is meant by the $\mathrm{C}$ costs. Probably, in this case, the difference in costs for the compared gas cleaning systems can be considered. In our opinion, difficulties are eliminated when moving to relative values (for example, calculating $\mathrm{D}_{\text {pr }}$ per ruble of costs). We can note that penalties for environmental pollution should be included in the costs of upgrading existing facilities.

The economic efficiency of environmental protection measures, assessed by the correlation (4.97), must comply with the $\mathrm{E} \rightarrow \max$ condition, rubles/t. In this case, the proposed criterion for assessing the effectiveness of environmental protection measures $\theta$ that satisfies the conditions will be more convenient.

$$
\theta=\frac{\ni}{\Im_{0}} \rightarrow \max >1,0
$$

where $\mathrm{E}_{0}$ is the economic efficiency of the basic version of the equipment. Correlation (4.99) is convenient to use in the same climatic zone, where the duration of the equipment operation does not differ significantly. To assess the operation of the treatment equipment in different climatic zones, it is proposed to additionally take into account the operating time factor, using an additional factor $\tau^{-}$in expression (33), writing it as

$$
\theta \bar{\tau}=\theta \frac{\tau}{\tau_{0}} \rightarrow \max \geq 1
$$


where $\tau_{0}$ is the operating time of the basic version of the equipment.

Given the above, using the proposed methodology it seems possible to assess the expected damage to the environment, the economic efficiency of the project being developed, and select the most profitable area for the location of dust-cleaning equipment at the design stage already.

\section{Conclusion}

1. For the development of economic policy and making optimal economic decisions, it is important to know the economic value of goods and services;

2. Currently, most natural factors either have no price at all or have an understated estimate, which often leads to the adoption of nature-intensive anti-ecological decisions;

3. Underestimation of environmental parameters leads to a distortion of the analysis of economic development through traditional indicators of the gross national product, etc., the growth of which may cover the environmental degradation.

4. The accepted methods for assessing environmental damage and environmental efficiency are global in nature and do not take into account the design features of gas cleaning systems (in particular, gas cleaning of asphalt mixing plants), which does not allow an expert assessment of the environmental perfection of devices and instruments at the design stage already or at the stage of technical, economic and ecological justification of the proposed design solutions.

A new method for assessing the prevented economic damage during environmental protection measures has been developed, which takes into account various technical and design features of dust cleaning systems. A criterion for evaluating the effectiveness when comparing installations of various designs were proposed.

\section{References}

1. V.A. Kulagin, T.A. Kulagina, A.I. Matushenko, J. Sib. Fed. Univ. Eng. \& Technol. 6, 123 (2013)

2. T.A. Kulagina, V.A. Kulagin, V.V. Moskvichev, V.A. Popkov, Ecology and Industry of Russia 20, 4 (2016). https://doi.org/10.18412/1816-0395-2016-10-4-10

3. V.V. Shelenkova, T.A. Kulagina, Radioactive waste 14, 28 (2021). DOI: $10.25283 / 2587-9707-2021-1-28-38$

4. T.A. Kulagina, O.A. Kozin, V.A. Popkov, Radioactive waste management (Krasnoyarsk, Grotesque Publ., SFU, 2018), 183 p.

5. T.A. Kulagina, V.A. Kulagin, Radioactive waste 11, 75 (2020). DOI: 10.25283/25879707-2020-2-75-84

6. T.A. Kulagina, S.A. Ivanov, J. Sib. Fed. Univ. Eng. \& Technol. 13, 965 (2020). DOI: 10.17516/1999-494X-0276

7. T.A. Kulagina, V.A. Kulagin, A.I. Matushenko, Technosphere safety in nuclear power (Krasnoyarsk: Grotesk, SibFU, 2014), 286 p.

8. T.A. Kulagina, O.A. Kozin, A.I. Matyushenko, Environmental security of technosphere objects (Krasnoyarsk: Grotesk, 2015), 323 p.

9. O.G. Dubrovskaya, V.A. Kulagin, Yao Limin, J. Sib. Fed. Univ. Eng. \& Technol. 13, 991 (2020) DOI: 10.17516/1999-494X-0280

10. O.G. Dubrovskaya, V.V. Evstigneev, V.A. Kulagin, J. Sib. Fed. Univ. Eng. \& Technol. 4, 629 (2011)

11. O.G. Dubrovskaya, V.A. Kulagin, Yao Limin, IOP Conf. Ser.: Mater. Sci. Eng. 941, 012009 (2020). doi:10.1088/1757-899X/941/1/012009 
12. O.G. Dubrovskaya, V.A. Kulagin, E.S. Sapoghnikova, Feng-Chen Li, Qian Li and ZhiYing Zheng, J. Sib. Fed. Univ. Eng. \& Technol. 8, 369 (2015)

13. V.A. Kulagin, O.G. Dubrovskaya, D.N. Gudkov, A.I. Matyushenko, IOP Conference Series: Earth and Environmental Science 288, 12013 (2019). DOI: 10.1088/17551315/288/1/012013

14. O.G. Dubrovskaya, V.A. Kulagin, J. Sib. Fed. Univ. Eng. Technol. 12, 460 (2019) DOI: 0.17516/1999-494X-015

15. Zheng Z Y, Qian Li, Feng-Chen Li, Vladimir A. Kulagin, Sci China Tech Sci 58, 1 (2015). doi: 10.1007/s11431-015-5827-y;

16. D.S. Likhachev, Feng-Chen Li, Vladimir A. Kulagin, Sci. China. Tech. Sci. 57, 2115 (2014). doi: 10.1007/s11431-014-5631-0

17. V.A. Kulagin, V.V. Moskvichev, N.A. Makhutov, D.M. Markovich, Yu.I. Shokin, Her. Rus. Acad. Sci. 86, 454 (2016). DOI: 10.1134/S1019331616060034

18. Zhi-Ying Zheng, Qian Li, Lu Wang, Li-Ming Yao, Wei-Hua Cai, Vladimir A. Kulagin, Hui Li, Feng-Chen Li Desalination 455, 1 (2019). doi.org/10.1016/j.desal.2018.12.012

19. V.A. Kulagin, T.A. P'yanykh, Chem Petrol Eng 50, 24 (2014). DOI 10.1007/s10556014-9848-3

20. V.A. Kulagin, L.V. Kulagina, Feng-Chen Li Fundamentals of Cavitation Treatment for Multicomponent Environments (Moscow, RU-SCIENCE, 2017), 182 p.

21. Yu-Ke Li, Zhi-Ying Zheng a, Hong-Na Zhang, Feng-Chen Li a, Shizhi Qian, Sang Woo Joo, Ludmila V. Kulagina, Computers \& Fluids 152, 57 (2017) http://dx.doi.org/10.1016/j.compfluid.2017.04.016

22. V.M. Ivchenko, V.A. Kulagin, A.F. Nemchin, Cavitation technology (Krasnoyarsk: Publishing House of KSU, 1990), $200 \mathrm{p}$.

23. N.D. Demidenko, V.A. Kulagin, U.I. Shokin, F.-C. Li, Heat and Mass Transfer and Supercavitation (Novosibirsk, Nauka, 2015), 436 p.

24. M.P. Baranova, V.A. Kulagin, Physics and Chemical Basics of Obtaining Fuel Water Suspensions (Krasnoyarsk, IPC SFU, 2011)160 p.

25. M.P. Baranova, L.V. Kulagina, V.M. Ekaterichev, Physics and Chemical Foundations of Industrial Heat Technologies (Krasnoyarsk, Grotesk, 2018) 148 p.

26. V. Kulagin, T. Kulagina, E. Nikiforova, D. Prikhodov, A. Shimanskiy, Feng-Chen Li IOP Conf. Ser (2018)

27. V. Murko, V. Khyamyalyainen, M. Baranova, E3S Web of Conferences 41, 01042 (2018) https://doi.org/10.1051/e3sconf/20184101042;

28. V.I. Murko, A.K. Dzhundubaev, M.P. Baranova, A.I. Biybosunov, V.A. Kulagin Hydrotransport fuel and energy complexes. Russian-Kyrgyzstan scientific and technical cooperation in the field of thermal power (Krasnoyarsk, Sib. Feder. Un-t, 2015) $250 \mathrm{p}$.

29. A.V. Shchuykov, A.V. Ruykov, V.A. Kulagin, A.Y. Radziuk, Industrial Energy 8, 911 (2011)

30. M.P. Baranova, V.A. Kulagin, Zhi-Ying Zheng, Qian Li, Feng-Chen Li, D.S. Likhachev Limin, J. Sib. Fed. Univ. Eng. \& Technol. 4, 474 (2014)

31. A.V. Zhuikov, V.A. Kulagin, M.P. Baranova, D.O. Glushkov, Therm. Eng. 63, 870 (2016). DOI: 10.1134/S0040601516120107

32. N.D. Demidenko, L.V. Kulagina, Chem Petrol Eng. 42, 128 (2006) DOI: 10.1007/s10556-006-0065-6

33. T.A. Kulagina, The effectiveness of preparatory processes for the combustion of waterfuel mixtures in small-volume furnaces (Krasnoyarsk, Siberian Federal University) 353 p. (2009) 